\title{
MIDAS
}

Museus e estudos interdisciplinares

$3 \mid 2014$

Varia e dossier temático: "Museos y participación biográfica"

\section{A Casa da Cerca, um projeto de autor: 20 anos de programação para o diálogo}

Casa da Cerca, a project with signature: 20 years of programming for dialogue

\section{Emília Ferreira}

\section{(2) OpenEdition}

\section{Journals}

Edição electrónica

URL: http://journals.openedition.org/midas/570

DOI: $10.4000 /$ midas. 570

ISSN: 2182-9543

\section{Editora:}

Alice Semedo, Paulo Simões Rodrigues, Pedro Casaleiro, Raquel Henriques da Silva, Ana Carvalho

\section{Refêrencia eletrónica}

Emília Ferreira, "A Casa da Cerca, um projeto de autor: 20 anos de programação para o diálogo », MIDAS [Online], 3 | 2014, posto online no dia 09 junho 2014, consultado no dia 02 maio 2019. URL : http://journals.openedition.org/midas/570; DOI : 10.4000/midas.570

Este documento foi criado de forma automática no dia 2 Maio 2019.

\section{cc) (†) (อ)}

Midas is licensed under a Creative Commons Attribution-NonCommercial-ShareAlike 3.0 International License 


\section{A Casa da Cerca, um projeto de autor: 20 anos de programação para o diálogo}

Casa da Cerca, a project with signature: 20 years of programming for dialogue

\section{Emília Ferreira}

\section{Introdução}

1 Poucos projetos museológicos terão uma vertente tão personalizada (ou com participação biográfica) como a Casa da Cerca-Centro de Arte Contemporânea. Equipamento da Câmara Municipal de Almada, aberto ao público a 18 de novembro de 1993, a Casa da Cerca ${ }^{1}$, como é conhecida, mantém-se a Casa do Desenho, espaço no qual se investiga, expõe, discute e pratica o desenho. Não é por acaso.

2 Desde o primeiro momento da sua história como espaço público, a Casa da Cerca surge associada ao seu primeiro diretor, o pintor e professor Rogério Ribeiro (1930-2008) (autor do programa da Galeria Municipal de Arte, aberta ao público em 1988), convidado pela autarquia para elaborar os projetos de investigação, museológico e de equipamento (Afonso 2008). Mesmo após o seu desaparecimento, em 2008, o centro oferece uma continuidade programática que lhe confere um particular cunho identitário.

Dedicada essencialmente à pesquisa em torno dessa disciplina central e aglutinadora, devido a um interesse artístico e pedagógico caro a Rogério Ribeiro, ele próprio um desenhador compulsivo e professor na Faculdade de Belas-Artes de Lisboa, a programação da Casa da Cerca tem obedecido a um eixo que, com inflexões para a modernidade e algumas contaminações com outras áreas, já anunciadas na primeira grande exposição temática e de investigação, O Desejo do Desenho (1995), se tem mantido atenta ao exercício e à pesquisa histórica e plástica desta disciplina, entendida como desígnio e processo de pesquisa, registo expressivo e materialização final da criação artística, demonstrando a 
abrangência do conceito e o quanto permite aos criadores a exploração de abordagens e media diferenciados. ${ }^{2}$

Com críticas no percurso por parte de algum público, artistas e críticos que gostariam de ver no espaço uma programação, porventura, considerada mais contemporânea, ou seja, com maior incidência no vídeo, instalação e fotografia e menor presença de desenho, contudo, o centro tem insistido nessa via identitária apesar das dúvidas e incertezas. A nova direção e os vários membros da equipa têm operado algumas inflexões, procurando manter a linha de investigação inicial, embora atualizando-a e polemizando-a.

5 Afinal, até que ponto a mudança, per se, não implica perda de identidade? Esta questão tem motivado amplo debate na instituição, em especial num momento em que o aumento do número de espaços municipais de vocação expositiva, por um lado, e a crise económica, por outro, obrigam a um repensamento de políticas culturais (o que expor, para quem, como o comunicar?) e financeiras (que projetos manter? Como justificar essas opções?).

\section{Localização e características, uma imagem envolvente}

Instalado numa antiga quinta de recreio setecentista, cuja habitação solarenga foi erigida no topo da arriba sobranceira ao rio Tejo, em frente a Lisboa, a localização privilegiada deste espaço cultural conserva um atrativo inesgotável. Após secular uso como habitação, a antiga Quinta da Cerca, compreendendo edifício e envolvente, foi adquirida pela Câmara Municipal de Almada, em 1988. As obras de adaptação não alteraram a traça e o edifício manteve assim as suas principais características, o que significa ter conservado a imagem solarenga. A relação com o visitante revela-se, portanto, de acolhimento. E se, por vezes, tal imagem pode constranger a entrada aos menos atentos à sinalética, por temerem introduzir-se num espaço privado, doméstico, ela oferece, uma vez ultrapassado esse obstáculo, um sentimento de pertença. ${ }^{3}$ 


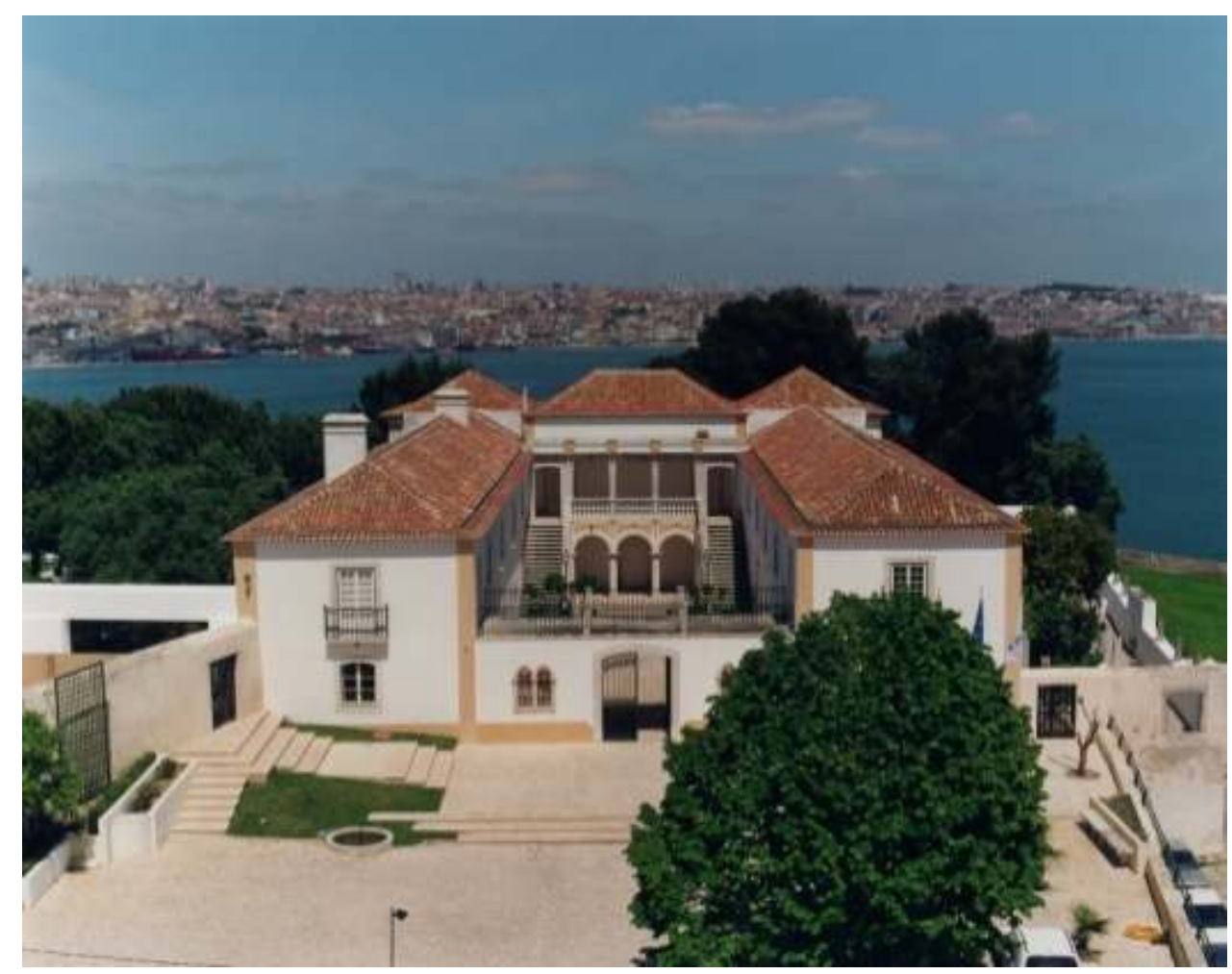

Fig. 1 - Vista geral do edifício da Casa da Cerca, com o rio Tejo e Lisboa ao fundo. É visível o enquadramento geográfico e a sua planta em $U$, com uma ala para nascente, outra para norte (olhando para Lisboa) e outra para poente

FOTOgRAfIA DE JOAQUIM NABAIS. ARQUIVO DA CASA DA CERCA @ CÂMARA MUNICIPAL DE ALMADA

\section{Relações com o exterior, exposições e investigação}

Para ampliar o sentimento de pertença, desde a sua abertura ao público, o centro teve sempre nos seus objetivos, e além de um projeto mais vasto e de maior ambição em termos nacionais, a dinamização cultural e artística do centro histórico de Almada e a formação abrangente de novos públicos, algo que tinha em comum com praticamente qualquer outro espaço museológico ou expositivo criado dentro da filosofia da nova museologia, sendo a diferenciação operada pelo seu projeto programático.

De início, o trabalho da equipa focava essencialmente a investigação e a criação de conteúdos para as exposições e catálogos. Contudo, desde a primeira exposição, inaugurada a 18 de novembro de 1993, a oferta de visitas orientadas teve imediata procura por parte das instituições escolares do concelho ${ }^{4}$.

9 Ao tempo, esse serviço era garantido pelas investigadoras responsáveis pela criação de conteúdos expositivos e de catálogos. Não tendo ainda uma definição clara de serviço educativo, a oferta apostava sobretudo na passagem de informação. Apesar do cunho académico, hoje considerado datado, essas visitas orientadas, num modelo que poderíamos definir como palestra de cunho curatorial, contribuíram desde logo para o aprofundamento dos laços entre o espaço expositivo e a comunidade escolar almadense ${ }^{5}$.

10 Mais uma vez, o lado pessoal significou um inequívoco peso nas opções tomadas quer na programação, quer na investigação, na comunicação e no registo. 0 facto de o primeiro diretor ser professor, de a pedagogia e a investigação representarem dois grandes eixos 
de interesses pessoais e profissionais, fez com que se rodeasse de uma equipa de especialistas, com formação em belas-artes e história da arte ${ }^{6}$, cujas valências lograram a continuação do programa, a sua clara divulgação ${ }^{7}$ e a sua ampliação. Nesse sentido, também, cedo foi pensada a criação do núcleo embrionário do atual centro de documentação especializado em desenho e em artistas portugueses contemporâneos (e dirigido a investigadores). Aberto ao público em 2008, o Centro de Documentação e Investigação Mestre Rogério Ribeiro ${ }^{8}$, cuja organização inicial se ficou a dever à então documentalista da equipa ${ }^{9}$, tem sido desde 1998 redefinido e organizado pela sua segunda coordenadora ${ }^{10}$.

\section{Serviço educativo}

11 Em 1997, foi formalmente organizado o serviço educativo (SE). Com um projeto mais abrangente ${ }^{11}$, oferecia uma componente pedagógica e lúdica, permitindo aos mais jovens um primeiro contacto com atividades plásticas de caráter criativo, entendendo-se, neste contexto, a criatividade como espaço à expressão pessoal. Quando, a partir de 1998, o SE começou a propor programas relacionados com as exposições, estes não consideravam, ainda, as visitas orientadas para o público escolar, a partir do ensino secundário. Para esse público, as visitas continuavam a ser da responsabilidade das investigadoras, mantendo uma abordagem mais teórica.

12 Antes de prosseguir, urge relembrar que, em 1997, a oferta de serviços educativos estava concentrada em alguns museus nacionais ou em instituições com indiscutíveis recursos financeiros e humanos, como a Fundação Calouste Gulbenkian ou a Fundação de Serralves, por exemplo, não significando, por isso, uma oferta considerada incontornável num centro de arte em contexto municipal ${ }^{12}$. Também era, em geral, um serviço prestado por profissionais de áreas científicas como a psicologia e as belas-artes, pelo que as abordagens teóricas ${ }^{13}$ não constituíam oferta regular ao público. A proposta desenvolvida na Casa da Cerca, a partir de então, prendeu-se, por isso, com uma vontade de sensibilizar o público jovem para atividades criativas, no âmbito de um ensino informal que desde o primeiro momento teve clara a necessidade do diálogo, equilibrando a participação do visitante com a informação dada pelo educador, como elemento fundamental para a aprendizagem (Hooper-Greenhill 1999, 4).

13 A partir de 1998, com a exposição de Alvar Aalto, o SE repensar-se-ia, passando a oferecer oficinas que esclareciam e refletiam sobre os conteúdos expositivos. Então, as propostas criadas, ainda maioritariamente dirigidas ao público escolar, eram já forjadas numa abordagem que convidava os visitantes, por muito jovens que fossem (uma das novidades do SE foi a criação de propostas para crianças de três anos, sendo, ao tempo, um dos primeiros espaços a desenvolver programas para esta faixa etária), a ler o que encontravam, de modo ativo, orientados por perguntas numa perspetiva inspirada em Vygotsky (2009), e aproximações lúdicas. Em termos das oficinas, também cedo se apostou na oferta de caminhos que explorassem as propostas dos autores com obra em exposição sem, contudo, se imitar o seu trabalho; compreender os pressupostos e reinventá-los, com materiais inabituais no ensino formal, continua a ser uma das apostas do SE.

14 Em 2000, a equipa sofreu alterações ${ }^{14}$. A partir de então, o SE reorganizou-se, oferecendo visitas-jogo e oficinas pedagógicas dos três anos aos seniores ${ }^{15}$; e visitas orientadas a públicos escolares e não escolares, a partir dos 15 anos de idade ${ }^{16}$. Acentuou-se, além disso, a ligação com o setor expositivo, tanto na preparação das atividades pedagógicas, 
como na conceção e montagem de algumas exposições. 0 diálogo estabelecido entre as duas áreas profissionais levou à criação de um projeto de publicações para o público infantil, de que resultaram dois volumes: a Casa com Jardim (2009) e Pintar com Rogério Ribeiro (2013) ${ }^{17}$. O paradigma da comunicação alterou-se também, passando as visitas orientadas a enquadrar a experiência prévia do visitante e o diálogo em torno do objeto artístico como uma mais-valia ${ }^{18}$, filiando-se nas novas pedagogias regenerativas (Acaso 2011).

15 Em termos expositivos, também o desenho do espaço é pensado de modo a permitir elementos extra de surpresa que motivem a visita, potenciando o fator lúdico. Por não se tratar de um museu, mas de um centro, a rotação expositiva anual é significativa (uma média de dez exposições por ano, considerando também as que resultam diretamente da atividade do SE), sendo mais um elemento de sedução do espaço.

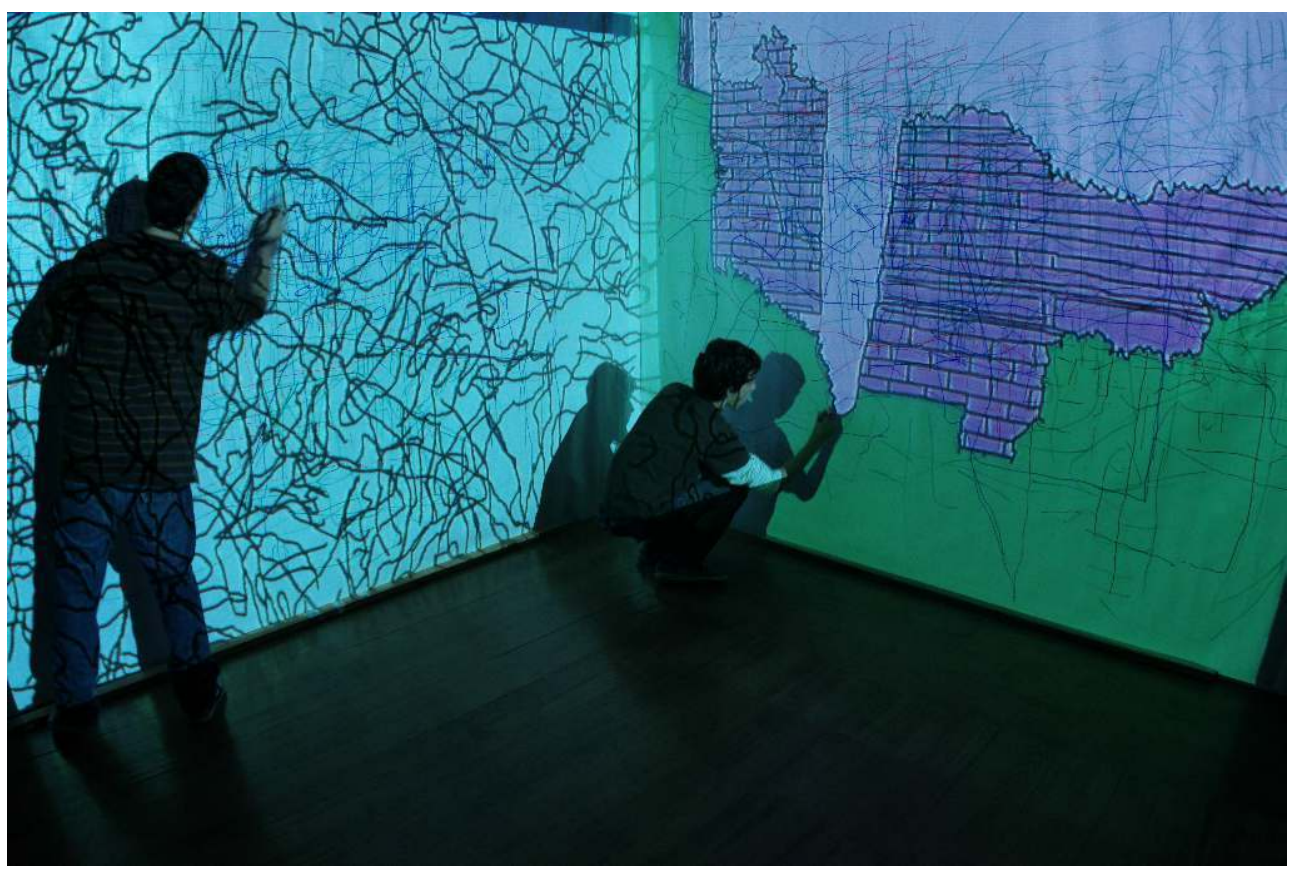

Fig. 2 - Atividade do SE na exposição individual de Pedro Calapez, Branca e Neutra Claridade, em 2008 (C) Arquivo da Casa da Cerca 


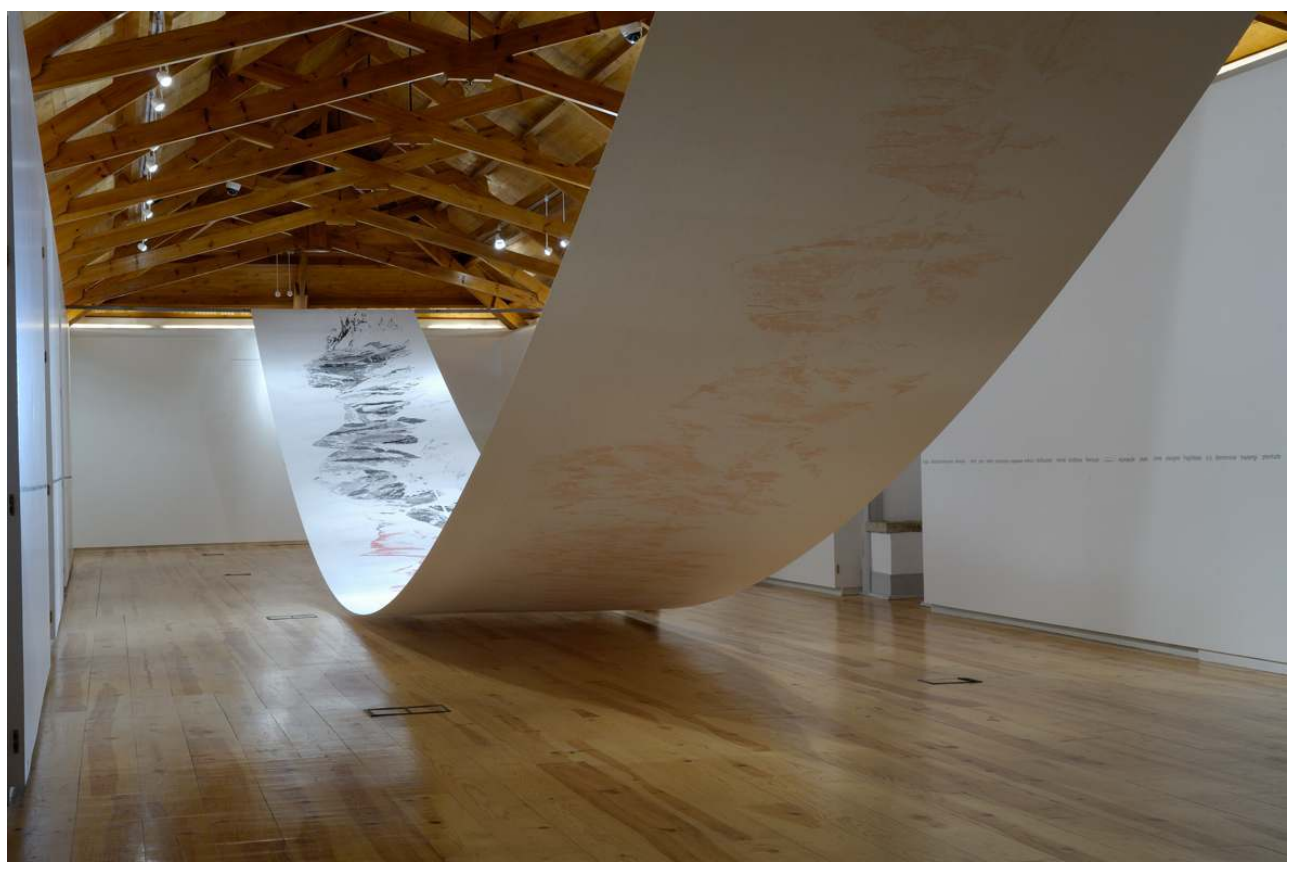

Fig. 3 - Exposição individual de Cristina Ataíde, Suspender o Ar, 2010. Desenho de 25 metros concebido de propósito para este espaço

(c) Arquivo da Casa da Cerca

16 Em 1997, foi organizada a primeira exposição de arquitetura e as primeiras conversas em torno de temas de investigação ${ }^{19}$. Esse modelo, com as variáveis consideradas mais adequadas a cada caso, tem continuado, recorrendo-se a convidados especialistas e ao contributo dos investigadores da equipa.

Outro elemento de diálogo tem sido a programação de palestras, conferências e cursos livres, concebidos e ministrados por elementos da equipa, numa abordagem parcialmente maiêutica, de novo integrando uma corrente mais recente de repensamento da função do educador (Burnham e Kai-kee 2012). Com destinatários que se desejam oriundos de camadas etárias diversificadas, bem como com níveis e áreas de conhecimento heterogéneos, e sem perder de vista o rigor científico da investigação a montante, os cursos oferecem narrativas abrangentes que iluminam o contexto criativo, estabelecendo, por exemplo, relações com a história do pensamento, costumes, ciência e literatura. $\mathrm{O}$ tom assume, assim, o compromisso entre ciência e narrativa (storytelling), cativando o público e tornando-o mais participativo - toda a gente tem estórias para contar... (Gottschall 2012). 


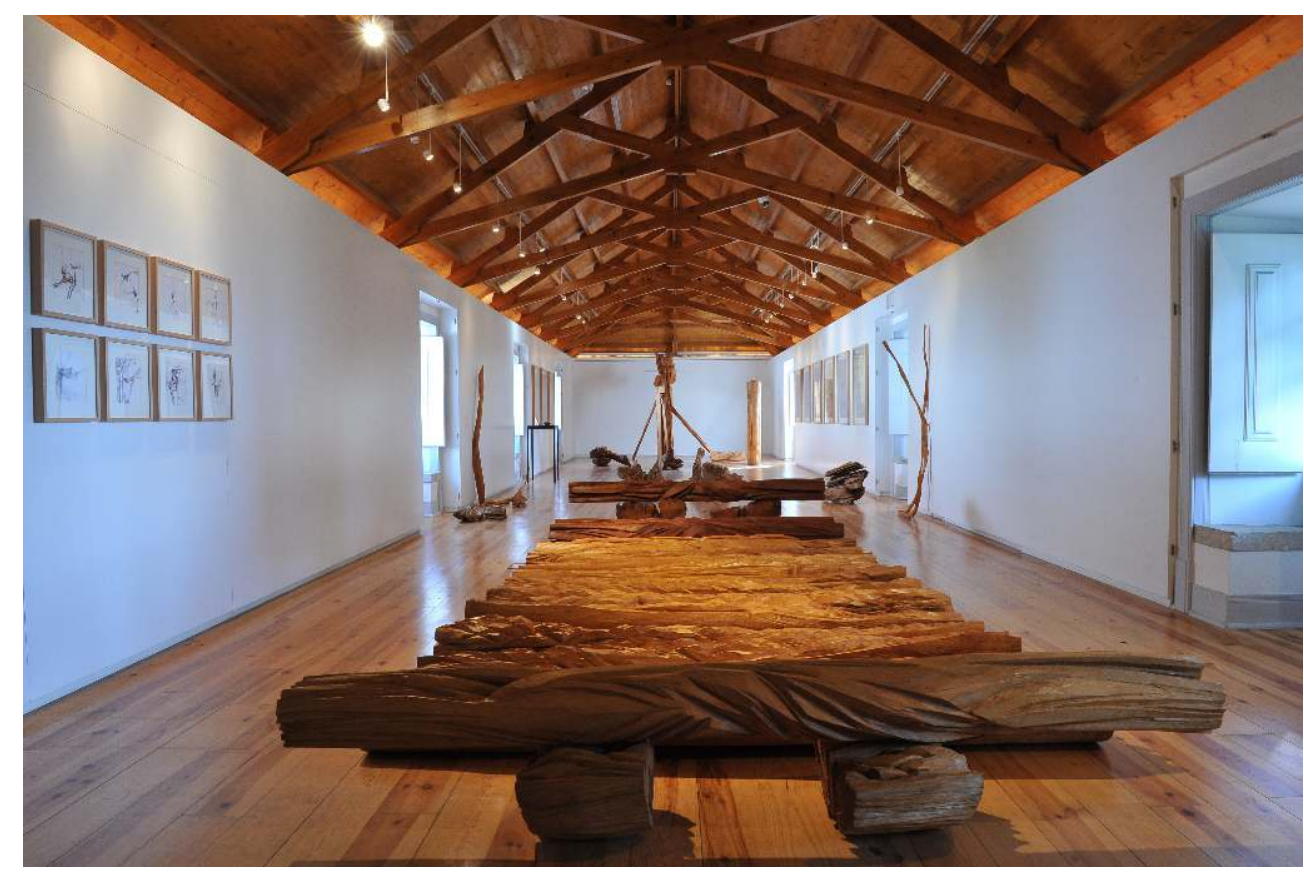

FIg. 4 - EXPOSIÇÃo INDIVIDUAL dO ESCULTOR ALBERTO CARNEIRO, EM 2011. EXEMPLO DE RELAÇÃo EXPOSITIVA DE DESENHO E ESCULTURA. NESTA EXPOSIÇÃO, POR INDICAÇÃO EXPRESSA DO ESCULTOR, AS OBRAS PODIAM SER TOCADAS, O QUE SE REVELOU PARTICULARMENTE APETECIDO PELOS VISITANTES

(C) Arquivo da Casa da Cerca

\section{O Chão das Artes - Jardim Botânico}

Em junho de 2001, foi inaugurado o Chão das Artes - Jardim Botânico. Iniciativa pioneira na especificidade da articulação das vertentes científica e artística, foi concretizada num projeto inspirado no jardim tradicional português de quinta de recreio (origem da Casa da Cerca) que, além da estufa e anfiteatro de ar livre, se organiza em seis áreas estruturantes, nas quais crescem plantas, cujos componentes originam materiais usados nas artes plásticas ${ }^{20}$.

19 A mostra documental e artística que acompanhou a inauguração do Chão das Artes, Natura Artis Magister. A Natureza Mestra das Artes, estabeleceu uma primeira linha de leitura que cruzou a história das ciências com a da cultura. Além de aspetos tecnológicos, foram também abordados temas do domínio da alquimia, simbologia, ilustração científica, história dos jardins e representação da paisagem na arte portuguesa do século XIX.

Em 2011, na comemoração dos dez anos do jardim e já com novas alterações na equipa ${ }^{21}$, esse fio de relação entre arte e natureza foi retomado. Desta vez, a coletiva Sobre-Natural 10 Olhares sobre a Natureza, evento central do programa de comemorações do décimo aniversário do Chão das Artes, e prosseguindo as questões apontadas em 200122, observava então a natureza do ponto de vista do desenho contemporâneo, incluindo a ilustração botânica. 


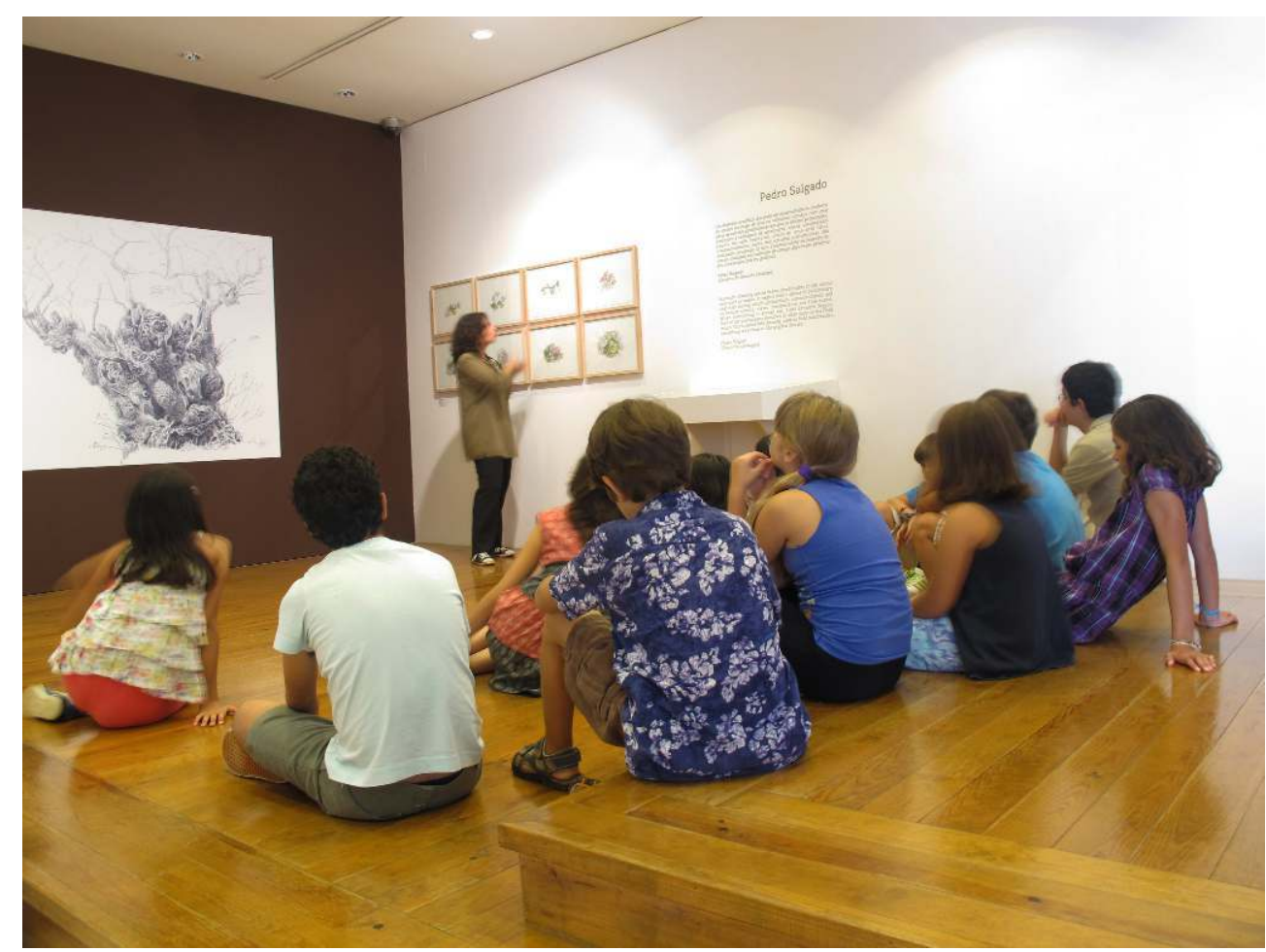

FIg. 5 - VISITA ORIENTADA À EXPOSIÇÃo SOBRE-NATURAL - DEZ OLHARES SOBRE A NATUREZA, EM 2011

(C) Arquivo da Casa da Cerca

Refletindo as propostas da investigação, os dez autores ${ }^{23}$ que integraram esse projeto (cinco ilustradores científicos e cinco artistas plásticos contemporâneos) concretizaram um diálogo profícuo, patente na colocação das obras no espaço, sem discursos de fragmentação, conferindo ampla oportunidade para uma reflexão abrangente da pluralidade das linguagens e pressupostos.

Conceptualmente, esta exposição prosseguiu a linha programática de investigação histórica, desta vez debruçando-se sobre a história da ilustração científica ${ }^{24} \mathrm{e}$ da sua relação com o mimetismo e o conhecimento nas artes, constituindo-se como mais um espaço de discussão sobre a atualidade e a pertinência do desenho, tanto no registo expressivo e estético, como no rigoroso traçado do projeto científico. Do ponto de vista do público, foi uma das mais visitadas, pela dupla vertente envolvida, tendo tido especial eco entre as escolas.

Em termos pedagógicos, o Chão das Artes tem oferecido um leque crescentemente alargado de possibilidades, a que não é alheio o entendimento da atual responsável. A recuperação de diálogo transversal (entre áreas científicas, dentro da equipa) abriu caminho à investigação sobre a história e elaboração de materiais (suportes, tintas, riscadores) e à exploração de técnicas ${ }^{25}$, levando a um nível mais aprofundado os conhecimentos comuns sobre a disciplina. Esse tipo de oficinas (p. ex. papel de fibras como o algodão e fabrico de papiros; tintas vermelhas e negras; desenho com carvão vegetal fabricado a partir de plantas do jardim; goma-arábica ${ }^{26}$ ) tem tido muita procura por parte do público em geral. A descodificação dos elementos materiais das artes, tornando-a tangível, tem sido um dos maiores sucessos do $\mathrm{SE}^{27}$ relacionado com o Chão das Artes, mais uma vez refletindo a importância do envolvimento pessoal de quem o coordena atualmente. Na verdade, entendido de início, pela sua coordenadora de então, sobretudo como uma coleção de plantas com características específicas, com a atual 
responsável passou a ser concebido sobretudo como espaço de fruição, no qual existem plantas que estão a ser estudadas e experimentadas e cujo conhecimento está a ser partilhado.

Esse espaço de fruição, com trabalhos e cuidados particulares, convida voluntários para um dia de trabalho no jardim ${ }^{28}$ desde o início de 2013. Esse convite tem provado ser mais um sucesso, envolvendo participantes de todas as camadas etárias, muitos deles reiterando semanalmente a sua presença, que se estende por toda a envolvente verde da Casa da Cerca. Com efeito, esta não se reduz ao Chão das Artes. Além de uma área não visitável, contempla ainda, como zonas públicas, o Parque de Escultura e um outro núcleo de jardim, inaugurado em junho de 2012, o Jardim dos Leitores (adjacente ao centro de documentação), cujo desenho envolveu crianças no âmbito de um atelier temático, realizado em dezembro de 2011, e cuja plantação contou também com a participação de voluntários e de jovens de cursos de Educação e Formação de jardinagem, ao longo de várias semanas, na primavera de 2012.

O envolvimento do público (de diferentes idades e em momentos distintos da construção e manutenção destes jardins) tem oferecido a esses participantes um sentido de pertença e de bem público que contribui para o estreitamento das relações com a Casa da Cerca como um todo.

\section{Comunicar a Casa}

Outro relevante aspeto na história deste equipamento cultural foi a entrada para a equipa de uma especialista em comunicação cultural, em $2008^{29}$. O facto de a instituição ter passado a contar com esse saber para comunicar a sua atividade tem produzido efeitos muito benéficos no modo como esta é percebida no exterior. À parte a construção de uma página na internet da Casa da Cerca, da existência da newsletter, já com milhares de assinantes, a realização de uma festa anual que envolve a Casa da Cerca e jardins, num dia inteiro $^{30}$ de atividades lúdicas e culturais (mercado Crafts e Design, piquenique, Manta de Livros, oficinas plásticas para todas as idades, visitas orientadas às exposições patentes e ao jardim, música, teatro, massagens relaxantes, Ioga, Tai-chi, Slackline, etc.), tem contribuído de modo muito eficaz para a divulgação da instituição. Com as primeiras experiências, em 2009 e 2010, desde 2011 que a festa assumiu contornos mais definidos, passando a ser organizada em torno do mesmo mote que orienta a programação expositiva e de SE anual.

Tendo-se notado uma crescente ocorrência de situações em que as pessoas, quando interpeladas a propósito do centro, referiam já ter ouvido falar, o teaser da comunicação da edição de $2012^{31}$ foi: «Festa da Casa da Cerca. Já ouviu falar?». Em 2013, comemorandose duas décadas de atividade enquanto centro de arte contemporânea, o eixo da programação foi a própria Casa da Cerca. Assim, o mote da festa foi «Casa da Cerca. Ocupe-a! ${ }^{32}$, convidando o público a fazer desta a sua casa.

É pertinente sublinhar que a conceção, organização, produção, concretização e receção ao público são da responsabilidade da equipa. Todos os seus elementos, sem exceção, são envolvidos nesta organização, o que significa que, após as várias semanas de preparação, no dia da festa se sente um clima de envolvimento muito pessoal na receção ao público.

29 A festa tem vindo a demonstrar um muito relevante crescimento de visitantes e uma diversificação de públicos, de algumas centenas de visitantes no primeiro ano para vários 
milhares nos últimos dois anos. O facto também de se tratar de um evento de um dia inteiro (e noite), com capacidade para acolher famílias (com oferta de atividade ao longo de todo o dia), grupos de amigos, visitantes isolados, num espaço confinado, oferece também uma clara sensação de segurança. 0 envolvimento que então se cria é claramente repercutido na maior facilidade com que os visitantes regressam, mesmo aqueles que, por norma, não são frequentadores de espaços expositivos.

\section{Conclusão} personalizada (ou com participação biográfica) como a Casa da Cerca. Não só pelo modo como o seu programa foi inicialmente pensado, como também pelo facto de se manter central ao pensamento da instituição. Essa questão é tanto mais importante quanto o momento presente coloca desafios muito concretos às instituições culturais. multiplicação, nos últimos anos, de equipamentos culturais um pouco por todo o país (sabendo-se que muitos, contemporâneos da criação deste centro ou até mais recentes, se encontram encerrados por falta de pessoal qualificado para a sua gestão e/ou por ausência de meios financeiros mínimos) obriga ao repensamento crítico e rigoroso da sua programação. Tal como outros municípios do país, também Almada viu dilatada a sua oferta de equipamentos culturais. Com tanta e tão diversificada oferta e tão perto de Lisboa, com uma programação quantitativa e qualitativamente sedutora, o que levará o público a optar por um determinado projeto? o que levará o público a visitar a Casa da Cerca e a voltar?

Além da indiscutível atratividade da sua localização e do fator de interesse histórico do edifício (cuja história, contudo, permanece por publicar, o que constitui uma das barreiras mais importantes a suprir, dada a manifesta curiosidade dos visitantes); além da participação biográfica da equipa, elemento de diferenciação fundamental no envolvimento da população na opção pelas práticas pedagógicas regenerativas, muito permanece por fazer. A integração deste equipamento no plano turístico de Almada, concorrendo para a sua divulgação, sobretudo entre os estrangeiros, algo há muito perseguido pela equipa e cuja falência já tinha sido sublinhada (Carvalho 2010), a integração recente numa zona especial de proteção ${ }^{33}$, contribuem igualmente para manter o seu apelo turístico. A abertura recente de uma cafetaria ${ }^{34}$ também tem sido um fator de oferta no centro.

O maior problema da instituição continua a ser a falta de acessos ao primeiro piso (principal espaço expositivo) para cidadãos com mobilidade reduzida. Apesar disso, outros cidadãos portadores de deficiência encontram na Casa da Cerca resposta às suas necessidades.

A sua mais-valia permanece a sua oferta cultural, a especialização do seu programa e o envolvimento da equipa com o projeto. Tal situação prende-se com várias razões: uma delas, o facto de se tratar de uma equipa muito pequena ${ }^{35}$. A outra, os hábitos de trabalho que compreendem a criação de propostas e sua discussão em equipa ${ }^{36}$. E, por último, o facto de a instituição gozar de uma enorme liberdade de programação que estimula o envolvimento pessoal, dando depois ao resultado um cunho marcadamente identitário, 
em que, não perdendo de vista o projeto inicial, cada um oferece as suas capacidades, no maior contributo possível para o resultado final.

Em termos metodológicos, podemos dizer que, aliando o rigor da investigação à comunicação (que se pretende) clara, adaptada, no discurso direto, aos diversos públicos ${ }^{37}$ , ao longo das duas décadas de atividade, a Casa da Cerca ofereceu já uma significativa diversidade de propostas expositivas, entre mostras individuais (103 até ao final de 2013), coletivas e temáticas (38), tendo divulgado o trabalho de várias centenas de artistas nacionais e estrangeiros. Para conhecer essas exposições, assistir a conferências, debates e cursos livres e também para visitar o jardim e frequentar as festas anuais e outros eventos culturais, passaram por este equipamento cultural cerca de 220000 visitantes $^{38}$, dos quais cerca de 32000 eram estudantes, de todos os níveis de ensino ${ }^{39}$ e de todo o país (e mesmo alguns estrangeiros ${ }^{40}$, em programas de cooperação), que participaram em atividades pedagógicas (visitas orientadas e/ou oficinas).

Em termos de investigação original para as exposições, mais de 300 textos foram produzidos para catálogos ${ }^{41}$ (maioritariamente bilingues), significando um corpus de mais de 10200 páginas de pesquisa e reflexão sobre os artistas e a sua prática.

Ao longo de mais de 20 anos, a instituição tem conseguido ultrapassar o duplo preconceito popular da arte como um objeto de fruição de elites, e da contemporaneidade desse mesmo produto, tanto mais visto como inacessível quanto mais contemporâneo ou inovador se pressente e apresente. Além do mais, o facto de se tratar de um centro de arte inserido numa pequena cidade situada na área metropolitana da grande Lisboa, para todos os efeitos padecendo ainda de muitos dos males das urbes satélite ${ }^{42}$, poderia ter aumentado potencialmente o fosso de comunicação. Para o mitigar, toda a programação e atividades complementares têm vindo a assumir um claro papel de serviço público (Hooper-Greenhill 1999, 47) ${ }^{43}$.

Enquanto SE, como sempre, e tal como acontece um pouco por todo o mundo (cf. Burham e Kai-Kee 2012; Acaso 2011) também a chegada ao exercício da profissão de educador em contexto museal dos profissionais desta instituição surgiu de uma pluralidade de acasos, tendo a vontade inicial de comunicar o próprio fascínio pela arte, pela natureza e pelos modos de criar, acabado por se transformar, com o tempo, numa capacidade crescentemente informada e experiente, de modo a providenciar um serviço público que se pretende melhorado a todos os níveis. Isso resulta, vale a pena sublinhar, não de meios financeiros ou materiais ideais, mas de uma dedicação conscientemente pessoal e profissional da equipa que habita a Casa da Cerca todos os dias.

\section{BIBLIOGRAFIA}

Acaso, María, coord. 2011. Perspetivas: Situación Atual de la Educación en los Museos de Artes Visuales. Barcelona: Ariel.

Afonso, Lígia. 2008. "Casa da Cerca-Centro de Arte Contemporânea: Programar para

Descentralizar. Políticas Culturais, Autarquia e Comunidades.” Dissertação mestrado em 
Museologia e Património, Faculdade de Ciências Sociais e Humanas, da Universidade Nova de Lisboa.

Burnham, Rika, e Elliott Kai-Kee. 2012. La Enseñanza en el Museo de Arte: La Interpretación como Experiencia. Tradução de José Wolfer e Gabriel Lara. [Cidade do México]: Instituto Nacional de Bellas Artes y Literatura e Museo Nacional de San Carlos.

Carvalho, Ricardo. 2010. “Turismo, 'Marketing' e a Realidade Museológica.” Dissertação de mestrado em Turismo Cultural e Animação, Instituto Superior de Novas Profissões.

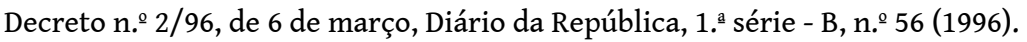

Ferreira, Emília. 2009. Casa com Jardim. Desenhos de Fernanda Fragateiro. Almada: Câmara Municipal de Almada.

Ferreira, Emília. 2013. Pintar com Rogério Ribeiro. Desenhos de Rogério Ribeiro. Almada: Câmara Municipal de Almada.

Gottschall, Jonathan. 2012. The Storytelling Animal: How Stories Make Us Human. Boston: Houghton Mifflin Harcourt.

Hooper-Greenhill, Eilean. 1999. The Educational Role of the Museum. Leicester Readers in Museum Studies. London: Routledge.

Moutinho, Mário. 1993. "Sobre o Conceito de Museologia Social." Cadernos de Sociomuseologia 1 (1): 7-9.

Portaria n.ํำ 48/2014, de 21 de janeiro, Diário da República, 2. série, n.ํำ 14 (2014).

Relatórios Anuais da Casa da Cerca: 1993-2013. Casa da Cerca-Centro de Arte Contemporânea. Material não publicado.

Simon, Nina. 2010. The Participatory Museum. Santa Cruz, Califórnia: Museum 2.0. http:// www.participatorymuseum.org/.

Varine, Hugues de. 2005. “O Museu Comunitário É Herético? Inquietações Amplamente Compartilhadas.” Tradução de OMP. Consultado janeiro 30, 2014. http://www.abremc.com.br/ artigos1.asp?id=9,.

Varine, Hugues de. 2013. Entrevista conduzida por Ana Carvalho a 19 de abril de 2013 na Faculdade de Ciências Sociais e Humanas da Universidade Nova, em Lisboa. http:// nomundodosmuseus.hypotheses.org/5585.

Vygostky, Lev. 2009. A Imaginação e a Arte na Infância. 2. ed. Tradução de Miguel Serras Pereira. Lisboa: Relógio d'Água Editores.

\section{NOTAS}

1. Classificado como Imóvel de Interesse Público (IIP), conforme Decreto n.o 2/96, o denominado Palácio da Cerca, em Almada, foi agora integrado numa zona especial de proteção (Portaria n.. 48/2014).

2. A mostra, $O$ Desejo do Desenho, inaugurou uma política de colaboração com outras instituições, contando-se então com a parceria da Fundação Luso-Americana para o Desenvolvimento, prosseguindo, em termos teóricos, uma via de investigação que se mantém. Ou seja, desde a história do desenho, a partir do Renascimento, até ao século XX, esclarecendo os múltiplos caminhos e opções do desenho na contemporaneidade, da diversidade formal e estética à material (dos riscadores aos suportes, passando pela inclusão de novas tecnologias como a 
projeção vídeo e técnicas fotográficas ao estudo dos materiais históricos do desenho; considerando que não existe contemporaneidade inovadora sem um claro conhecimento da tradição).

3. A sinalética, que já provou não ser eficaz, está em fase de repensamento.

4. De acordo com os nossos registos, a primeira visita orientada foi realizada a 26 de novembro de 1993 para alunos da Escola Secundária Emídio Navarro (Almada).

5. O programa de visitas orientadas teve, desde 1993, grande resposta junto do público escolar, embora este não esgote a procura. Também os ateliers de expressão plástica registam um número crescente de inscritos, do ensino pré-primário ao superior, incluindo grupos informais, de todas as idades. Embora, regra geral, os ateliers se desenvolvam em torno de temas sugeridos pelas exposições, existem propostas temáticas independentes da programação expositiva. (Por não ser esse o nosso âmbito de discussão, não nos deteremos aqui sobre a definição mais aturada de públicos, incluindo assim as escolas nesse conceito, de modo mais lato).

6. Tratava-se das pintoras Inez Wijnhorst e Cisela Björk, e das investigadoras, Renata Araújo e Ana Isabel Ribeiro.

7. Como notou Varine (2005), um dos problemas dos espaços museológicos foi a dicotomia entre especialistas, conhecedores dos objetos, mas distantes da população, e aqueles que embora próximos não detinham o conhecimento não podendo, por isso, partilhá-lo. o que Rogério Ribeiro sempre incentivou foi o rigor da investigação e do conhecimento aliado à clareza e ao gosto da partilha. Por exemplo, essa exigência revelar-se-ia também fundamental na confiança que as escolas depositam na Casa da Cerca como fonte de investigação e de passagem de conhecimento de modo claro, rigoroso e lúdico.

8. 0 centro tendo vindo a aumentar o acervo, sobretudo através de uma política de permutas e de doações de arquivos e bibliotecas pessoais de artistas e de algumas entidades (p. ex. Biblioteca de Arte da Fundação Calouste Gulbenkian, Cooperativa de Ensino Artístico - AR.CO, etc.). E, inicialmente, também por via da recolha de recortes de jornais e revistas já levados a cabo pela equipa, então também dirigida por Rogério Ribeiro, na Galeria Municipal de Arte (Almada) e pela doação de catálogos e livros de arte do próprio Rogério Ribeiro. Atualmente, o centro de documentação conta com 15300 títulos.

9. Com experiência profissional na Biblioteca da Associação dos Arquitetos, Ana Isabel Ribeiro é mestre em História da Arte, pelo que acumulou funções na investigação e na organização do fundo documental, criando também uma base de dados sobre artistas portugueses.

10. Ana Margarida Martins, chegada à Casa da Cerca com uma licenciatura em Antropologia e um mestrado em Museologia acabaria por fazer uma pós-graduação em Biblioteconomia.

11. Da responsabilidade da psicóloga Cristina Gameiro. Desde 2008, coordenadora do SE do Museu Coleção Berardo. Em 2011, o SE da Casa da Cerca passou a ser coordenado por Mário Rainha Campos, igualmente psicólogo de formação, com uma pós-graduação em Museus e Educação e experiência nos serviços educativos do Centro de Arte Moderna da Fundação Calouste Gulbenkian e do Museu Coleção Berardo, entre outros.

12. A Culturgest, por exemplo, só organizou o seu SE nos anos 2000.

13. Relembremos ainda que, em Portugal, as licenciaturas em História da Arte surgiram na década de 90 do século XX. Seria interessante avaliar o impacto que teve o boom de recémformados nessa área ao longo da década de 2000 nos serviços educativos do país.

14. Saem Renata Araújo (doravante docente de história da arte no ensino superior), Inez Wijnhorst e Cisela Björk (que prosseguem carreiras artísticas). Para o setor curatorial, em 2000, entrou Emília Ferreira, ao tempo, com mestrado em História da Arte, e com experiência na docência e em visitas orientadas no Centro de Arte Moderna da Fundação Calouste Gulbenkian. Mantêm-se uma jovem investigadora integrada na equipa em 1996, Catarina Rosendo (sairia em 2007, sendo substituída por outra investigadora oriunda da história da arte, Alexandra Canelas), uma documentalista, Ana Margarida Martins, que integrara a equipa em 1998; Cristina Gameiro e 
Ana Isabel Ribeiro que, em 2001, passou a dirigir a Casa da Cerca. Para a pertinência deste artigo, citamos apenas os membros da equipa que estiveram e/ou estão envolvidos na curadoria, na pesquisa e no SE.

15. Atividade da responsabilidade de Cristina Gameiro.

16. Atividade da responsabilidade de Emília Ferreira.

17. Projeto de Cristina Gameiro e Emília Ferreira, incluindo textos de Emília Ferreira.

18. Na Casa da Cerca não existe o hábito da criação de guião. Quando as visitas orientadas são realizadas por colaboradores externos, é-lhes passada toda a informação considerada pertinente, deixando-os coordená-la e transmiti-la de modo personalizado, contribuindo assim para o estabelecimento de uma relação de comunicação interpessoal mais direta. Assim, em geral, a abordagem proposta nos últimos anos na Casa da Cerca, opta por um enquadramento inicial às obras, incluindo aspetos técnicos/plásticos da criação/contexto. Mas esses dados são já fornecidos após o convite ao diálogo. O SE entende ser fundamental que o visitante, qualquer que seja o seu nível de escolaridade ou faixa etária, possa sentir-se livre para expressar aspetos da experiência que está a ter. De um modo geral, as apreciações, como qualquer profissional da área em qualquer lugar do mundo poderá constatar, comportam sempre algo de novo, motor de diálogo e de novas perspetivas mesmo para o educador especialista.

19. Exposição dedicada à obra do arquiteto Raul Chorão Ramalho.

20. As áreas são o jardim dos Pigmentos, no qual crescem espécies de cujas flores, folhas ou rizomas se obtêm pigmentos; o Pomar das Gomas, onde árvores de fruto, essencialmente do género Prunus, produzem as gomas utilizadas na pintura; o jardim dos Pintores, em cujos canteiros todos os anos se homenageia um pintor; o jardim dos óleos, onde se encontra rosmaninho, alecrim, alfazema, papoilas, linho e mais espécies produtoras de óleos usados na pintura; o jardim das Telas, com espécies como o linho e o algodão; e a Mata, dedicada às madeiras para escultura ou suporte de retábulos e às terebintinas e aos vernizes. Além destes núcleos estruturais, há ainda uma charca e tanques onde crescem papiros e outras plantas das quais se faz papel (para o papel, existe também uma larga zona de bambu).

21. Em 2008, havia saído a bióloga Cristina Coelho, anterior responsável pelo espaço, e no final de 2010 entrou para esse lugar a arquiteta paisagista Sónia Francisco, que, após um estágio profissional em Florença trabalhou vários anos nos jardins de Serralves.

22. E que, entretanto, haviam sido interrompidas com a saída de Cristina Coelho, em 2008.

23. Dez autores, evocando os dez anos do Chão das Artes.

24. Como núcleo histórico, esta mostra foi complementada por outra, que funciona até hoje, em autonomia. Intitulada As plantas do Chão das Artes. Ilustração botânica do séc. XVI ao séc. XIX é constituída por um conjunto de reproduções de antigas ilustrações botânicas pertencentes à coleção do Museu Nacional de História Natural do Jardim Botânico da Faculdade de Ciências da Universidade de Lisboa. As gravuras em questão foram retiradas de herbários, iluminuras, receituários, registos de expedições, diários de exploradores, tratados de medicina, floras, manuais de fitoterapia, livros de culinária, tratados de pintura, compêndios de botânica, artigos científicos, sublinhando os inúmeros usos das ilustrações botânicas. As reproduções escolhidas, que atualmente se encontram patentes no muro do Jardim, representam plantas que existem no Chão das Artes, todas elas com utilização nas artes plásticas. Dada a sua secular importância histórica e científica, e na impossibilidade de se expor quer os originais dessas gravuras, quer os livros em que foram publicadas pela primeira vez, foi selecionada quase uma centena de ilustrações, escolhidas entre inúmeras ilustrações publicadas numa dezena de obras, distribuída por cerca de cinquenta espécies, em trabalhos de diversos autores (nem sempre identificáveis), que cobrem um período do século XVI ao XIX. Na grande diversidade de registos patentes, oferecem-se diferentes olhares e técnicas sobre a mesma espécie. As peças reproduzidas foram originalmente realizadas em xilogravura, calcografia, litografia colorida à mão ou cromolitografia, evidenciando as exigências de qualidade e as técnicas disponíveis em cada 
época. Também por razões expositivas, foram quase todas reproduzidas em dimensões inferiores às originais, apresentadas por ordem alfabética do seu nome científico e, quando existem várias ilustrações da mesma espécie, por ordem cronológica. A sua leitura é facilitada pela organização referida e o público, mesmo o não iniciado, sente nesse material pedagógico um apoio científico e apelativo de abordagem ao jardim e à sua coleção de plantas, percebendo também a importância e a curiosidade que estas têm despertado em artistas e cientistas ao longo dos séculos.

25. A atual responsável pelo espaço, a arquiteta paisagista Sónia Francisco, tem vindo a investigar e a experimentar a produção de tintas negras e vermelhas, carvão vegetal, papiros e goma-arábica, entre outros materiais.

26. Não existindo acácias (Acacia verek) no Chão das Artes, a variante de goma-arábica produzida é obtida com recurso às prunóideas existentes no Pomar das Gomas.

27. Também já se realizaram experiências de tinturaria, nomeadamente com lãs.

28. Tendo em conta a diversidade de tarefas e cuidados que um jardim exige, os trabalhos com que os voluntários se deparam varia consoante a época do ano e as necessidades físicas do espaço. 29. Vanda Piteira, licenciada em Comunicação Cultural, tinha vasta experiência profissional na área (Ministério da Cultura), incluindo estudos de teatro e de gestão cultural.

30. Nos últimos anos, nos dias de festa, a Casa da Cerca abre ao público às 10 horas de sábado e encerra às duas da manhã de domingo. A entrada, como sempre, é gratuita.

31. Para um breve olhar sobre este evento veja-se http://www.youtube.com/watch? v=yCGbIQM7rUk (consultado em março 15, 2014) e http://www.youtube.com/watch? $\mathrm{v}=$ D68R0TbMYN8 (consultado em março 15, 2014).

32. A exposição central de 2013, cuja programação foi iniciada com uma exposição de pintura de Rogério Ribeiro A minha casa é a pintura, numa inequívoca homenagem ao primeiro diretor e mentor do projeto, teve como título Casa Ocupada. Formalmente inaugurada em outubro de 2013, desde a primavera que foram abrindo núcleos expositivos dessa mostra, revelando ao público espaços tradicionalmente privados do edifício e convidando à sua descoberta/ocupação. Sobre a montagem da primeira ocupação veja-se: http://www.youtube.com/watch?v=AWCUfHh7IKs (consultado em março 15, 2014) e sobre a edição de 2013 da festa consulte-se: http:// www.youtube.com/watch?v=CzFKFxZLOIU (consultado em março 15, 2014).

33. Ver nota 1.

34. Inaugurada a 22 de fevereiro de 2014, a cafetaria tem trazido à Cerca muita gente que nunca tinha entrado na instituição.

35. A equipa é constituída por 13 pessoas, compreendendo neste número jardineiros e cantoneiras. Os técnicos superiores são sete: Ana Isabel Ribeiro (direção), Alexandra Canelas e Emília Ferreira (curadoria), Mário Rainha Campos, incluindo Emília Ferreira e Sónia Francisco (SE), Vanda Piteira (comunicação e produção); Ana Margarida Martins (documentação) e Sónia Francisco (jardim botânico).

36. Mesmo que haja propostas individuais, nada é levado a cabo sem um trabalho conjunto.

37. As maiores satisfações que o SE guarda são confissões de visitantes, após oficinas ou visitas orientadas. Dois dos casos mais pungentes ocorreram com seniores: a felicidade de uma reformada, que começara a trabalhar na infância, e que nunca pintara com lápis de cor; ou uma reformada, analfabeta, que no fim de uma visita agradeceu a partilha do conhecimento dizendo: «eu sabia que isto era importante, porque está num museu; mas não compreendia e pensava que não era para mim; agora compreendo o que aqui está e fico feliz por ter percebido que afinal também posso cá vir, porque isto é para toda a gente.»

38. Dados até junho de 2013. Os registos apresentam um claro aumento do número de visitantes nos últimos anos.

39. 175 escolas de todo o país até ao início de 2013 (Relatórios Anuais da Casa da Cerca: 19932013).

40. São oferecidas visitas orientadas em português, inglês e francês. 
41. Na sua esmagadora maioria produzidos por membros da equipa. Noutros casos, da autoria de especialistas e críticos convidados.

42. Incluindo o preconceito da crítica e dos media.

43. Sobre o projeto foram já produzidas duas dissertações de mestrado: Afonso (2008) e Carvalho (2010). Têm igualmente sido realizados na Casa da Cerca vários estágios (comunicação, SE e jardins), dos quais destacamos o trabalho levado a cabo por Catarina França no âmbito do mestrado em Desenho da Faculdade de Belas-Artes da Universidade de Lisboa, da criação de dois guias do Chão das Artes para um público adulto e outro dirigido ao público infantil. A Casa da Cerca tem realizados protocolos com diversas instituições universitárias nacionais (Universidade Nova de Lisboa, Universidade de Évora, Universidade Técnica de Lisboa, Instituto Jean Piaget, Escola Superior de Educação de Setúbal, Politécnico de Tomar, etc.) e internacionais, e tem colaborado igualmente com escolas secundárias do concelho de Almada, acolhendo estágios de alunos de cursos profissionais.

\section{RESUMOS}

Aberta ao público em 1993, a Casa da Cerca-Centro de Arte Contemporânea, equipamento cultural da Câmara Municipal de Almada instalado numa antiga quinta de recreio setecentista, foi um projeto da autoria do pintor Rogério Ribeiro, a convite da autarquia. O programa inicial de investigação e divulgação da história e da contemporaneidade do exercício do desenho, mantémse até hoje. Amado por uns, criticado por outros e constantemente debatido no seio da instituição, ele vai sendo repensado por uma equipa que, mantendo o eixo do projeto inicial, o tem atualizado e, no processo, criado com os visitantes uma relação privilegiada, que tem aumentado e fidelizado os diversos públicos. Este artigo pretende oferecer o testemunho de um projeto com participação biográfica - e que até agora foi tema de duas dissertações de mestrado em museologia e turismo - e evocar algumas das estratégias da Casa da Cerca no relacionamento com a sua envolvente e os seus públicos, através da sua programação, num momento em que celebra 20 anos de atividade cultural.

Open to the public since 1993, Casa da Cerca-Contemporary Art Center, a cultural institution supervised by the Municipality of Almada and housed in an old eighteenth century leisure estate, was a personal project of painter Rogério Ribeiro. The initial program of researching and dissemination of the history and practice of Drawing and of its contemporary use, remains to this day. Loved by some, criticized by others, and permanently debated within the institution, this function is constantly updated by a team that, while cherishing the initial idea, has focused on involving visitors, creating a privileged relationship that sees rising loyal and diverse audiences. This article provides the testimony of a biographical and participatory project - which has hitherto received the scant attention of two dissertations on museology and tourism - and to evoke some of the various strategies used by Casa da Cerca to relate to its entourage and audiences, through its programming, on the 20th anniversary of its cultural activity. 


\section{ÍNDICE}

Palavras-chave: Casa da Cerca-Centro Arte Contemporânea, exposição, serviço educativo, comunicação, museu arte contemporânea

Keywords: Casa da Cerca-Contemporary Art Center, exhibition, educational department, communication, contemporary art museum

\section{AUTOR}

\section{EMÍLIA FERREIRA}

Licenciada em Filosofia pela Faculdade de Letras da Universidade de Lisboa; mestre em História da Arte pela Faculdade de Ciências Sociais e Humanas da Universidade Nova de Lisboa com uma dissertação subordinada ao tema História dos Museus Públicos de Arte no Portugal de Oitocentos: 18331884 (2001) e doutora em História da Arte com a tese Lisboa em Festa: a Exposição Retrospetiva de Arte Ornamental Portuguesa e Espanhola, 1882, Antecedentes e Materialização (2010), na mesma universidade; Integra a equipa da Casa da Cerca-Centro de Arte Contemporânea desde 2000, exercendo funções de curadoria e de serviço educativo. meofster@gmail.com 